\title{
Detection of the Modifiable and Non-Modifiable Risk Factors and the Adverse Consequences of Falling among Elderly People
}

\author{
Rokaia Fathi Mohammed ${ }^{1}$, Zainab Gazar Alagamy ${ }^{2}$ \&Tawheda Mohamed El-saidy ${ }^{3}$ \\ ${ }^{1 \cdot}$ Lecturer of Geriatric Nursing, Faculty of Nursing, Minia University, Egypt. \\ 2. Assistant Professor of Community Health Nursing (Geriatric), Faculty of Nursing, Fayoum University, Egypt. \\ 3. Assistant Professor of Geriatric Nursing, Faculty of Nursing, Menoufia University, Egypt.
}

\begin{abstract}
:
Background: Falling among elders is the most causative factor of unintentional injuries resulting in disability and hospitalization. Aim: Was to identify the modifiable and non-modifiable risk factors and the adverse consequences of falling among elderly people. Methodology: A descriptive study was conducted on 384 elderly participants at Minia governorate, Egypt. Tools: A structured questionnaire, Timed Up and Go Test Scale, Katz Scale, and MiniNutritional Assessment questionnaire were used. Results: Findings showed that $45.6 \%$ of the participants were at risk of falling based on the performed timed up and go test and $63.5 \%$ of them had a falling history. Female gender, age, and chronic diseases were the main non-modifiable risk factors, while the detected modifiable factors of falling included; absence of toilet seats (95.9\%), absence of grab bars $(76.2 \%)$, poor lighting $(56.6 \%)$, and slippery floor $(54.1 \%)$. Additionally, $93.4 \%$ had a lack of assistive devices, inactivity $(81.6 \%)$, anemia $(65.2 \%)$, and poor vision (50.8\%). Likewise, $73.0 \%, 35.2 \%, 26.6 \%$, and $100 \%$ of the fallers reported back pain, cut wounds, fractures, and fear respectively as adverse consequences. Conclusion: Hazardous environment, declined physical activities, walking problems, lifestyle, malnutrition, and body mass index were the most reported modifiable risk factors of falls. Recommendations: Early detection of the modifiable risk factors is essential for preventing falling and its adverse consequences among elderly people.
\end{abstract}

\section{Keywords: Consequences, Elderly, Falling, Modifiable, Non-modifiable \& Risk factors.}

\section{Introduction:}

Increased life expectancy and the number of older adults is a global challenge (Pigłowska et al., 2020). Falling among this increased segment of population is a major health issue that imposes high social and economic costs, and is considering the second leading explanation for unintentional injury related deaths worldwide (WHO, 2018). It had been reported that one in every three elderly persons (60 years and more) has falls annually, plus, elderly person who had experienced a fall tend to possess from two to three recurrent episodes of falls as reported by (National Center for Injury Prevention \& Control, 2015).

Falling is understood as unexpected event during which the person comes to rest on the ground, floor, or lower level, and excludes coming to rest against furniture, wall, or other structure (Florence et al., 2018). It can cause physical discomfort, affects the person's confidence and dependence, and can cause long-term health problems (Hopewell et al., 2018). Related literature reported that from $30 \%$ to $33 \%$ of elderly people having a minimum of once episode of falling per year (Soto-Varela et al., 2017). Institutionalized elderly people are three times more likely to possess falling than those who live in the community (Gomes et al., 2016).
In Egypt, it had been estimated that the prevalence of falls among Egyptian elderly persons was (35.3\%) with an increased incidence of falls among institutionalized than community dwelling older adults (Elsamahy et al., 2019). Although the geriatric homes are designed based on the needs of elderly, falls were found to be high $(50.0 \%$ to $66.0 \%)$ among Egyptian elders living in institutions versus one-third of community dwellings related to loss of family relationships, limited physical activities, and social isolation (Ismail et al., 2018).

With aging, there are multiple interrelated factors that can affect gait and balance like; co-morbidities (Morley et al., 2017), medication intake including diuretics and antihypertensive (Tinetti et al., 2014), and sensory impairments (Dolatabadi et al., 2018). All such factors can cause a decline in the ability of the elderly person to adequately react to the external disturbances such as slipping and stumbling, interfere with the daily living activities, and may increase the danger of falls (Jonkman et al., 2018). Most elderly group perceived that they are at threat of falling but they have a limited awareness regarding its contributing factors and how to prevent it (Maneeprom et al., 2018).

Several risk factors of falling are often preventable and modifiable include; malnutrition (Karavadi \& 
Raghuram, 2020), inadequate physical mobility and lack of exercise, living alone, insomnia, and obesity (Zhang et al., 2019), added to, environmental hazards such as; slipping, poor lighting, and wet floor (Mohammed et al., 2018). Likewise, poor footwear, improper use of assistive devices, and polypharmacy are also recognized as preventive predictors of falling among elders (Sharif et al., 2018).

Falling among elderly people is usually leads to negative physical consequences as cut wounds, bruising, fractures, disability, and limiting their functional capacity (Mohammed et al., 2018). Also, it can cause depression, isolation, alteration in body image, low self-esteem, and fear of falls as psychological consequences which affect about 26.0 $\%$ to $55.0 \%$ of elder adults (Bok et al., 2016). Plus the previous consequences of falls, it can cause immobility and dependency that features a direct effect on the family and caregivers due to the essential rehabilitation and extraordinary care (Ilha et al., 2014).

Accordingly, the recognition of the risk factors is important to prevent a considerable proportion of falling and to develop strategies to reduce falling and its adverse consequences among elderly people (Jankowska et al., 2018).

Nurses have an important role in preventing falls and limiting its adverse consequences as she is the first one who able to recognize patients' risk through using a comprehensive assessment tool, implement successful falls prevention programs, as well as, providing health teaching and counseling for elderly people and their caregivers on preventing or decreasing the incidence of falls (Abusaaq, 2015). Also, specific interventions such as balance training interventions, home safety assessment, and home modifications should be considered (Maggi et al., 2018).

\section{Significance of the study:}

Falls constitute a serious public health problem among the elderly people in Egypt (Ismail et al., 2018). The detection of risk factors is essential for prevention of falls and their complications at the primary and secondary level. Consistent with the last statistics from Central Agency for Public Mobilization \& Statistics, Egypt (2017), elderly people represented $6.3 \%$ of the total population in Minia governorate, Egypt. Despite the presence of a considerable percentage of that age group in Minia governorate, few studies are handling this health issue and focusing on identifying the modifiable and non-modifiable risk factors of falling and its adverse consequences among that most vulnerable age group. From this point, researchers attended to conduct this study.
Aim: The current study aimed to identify the modifiable and non-modifiable risk factors and the adverse consequences of falling among elderly people.

Research questions:

Q1-What are the modifiable risk factors of falling among elderly people?

Q2-What are the non-modifiable risk factors of falling among elderly people?

Q3-What are the adverse consequences of falling among elderly people?

\section{Subjects \& Method:}

Research design: A descriptive research design was used.

Setting: The current study was conducted at three geriatric homes (Abd-Elrahman, Omar Ebn Elkhatab, \& El Quedesa geriatric homes), and at the outpatient clinics of Minia university hospital (diabetic, orthopedic, ophthalmic, and medical clinics) in Minia City-Minia Governorate, Egypt.

Subjects: A total of 384 elderly persons were recruited for this study, (207) participants were from the mentioned outpatient clinics, and (177) residents from the three geriatric homes as the following; 72, 64, and 40 residents from Abd-Elrahman, Omar Ebn Elkhatab, and El Quedesa geriatric homes respectively.

Sampling: A convenience sample was recruited using the non-probability sampling technique. Firstly the researchers selected all convenient elderly residents from the previously mentioned geriatric homes who met the determined inclusion and exclusion criteria, and they were (177), after that the researchers completed the total estimated sample from the mentioned outpatient clinics of Minia university hospital, and they were (207) participants.

Inclusion criteria: Elderly people ( $\geq 60$ years) of both sexes, being alert, and agree to participate in the study.

Exclusion criteria: Elderly persons who had immobility, and who were unable to perform or to complete the Timed Up and Go test (TUGT).

\section{Calculation of the Sample Size:}

The researchers were used the web creative research systems sample size calculator website for calculating the specified sample size. It has been searched, reviewed, and checked for the calculated results supported known formulas for common research objectives (Meysamie et al., 2014). The sample size has been determined based on statistics about the number of elderly people at Minia governorate in 2017. The entire number was 344171 . With a $95 \%$ level of confidence (error $=5 \%$ ) and a study power of $95 \%$, and then required sample size was equal to 384 elderly persons. 
Tools of data collection: Four tools were used for data collection.

Tool 1: A structured interview questionnaire developed by the researchers after reviewing the recent related literatures as (Mohammed et al., 2018 \& Zang et al., 2019). It included three sections: 1) the personal data such as; age, sex, education, working condition, income, residence, and marital status. 2) Physical measurements such as; blood pressure, pulse, height, and body weight. Accordingly, body mass index (BMI) was calculated as weight in $\mathrm{kg}$ divided by the square of the height in meters $(\mathrm{kg} / \mathrm{m} 2)$, then body mass index (BMI) was classified into underweight $<18.5$, normal (18.5$24.9)$, overweight (25-29.9), and obese $\left(\geq 30 \mathrm{~kg} / \mathrm{m}^{2}\right)$ (WHO, 2006). The third section: Included assessment sheet about the risk factors and the adverse consequences of falls. The non-modifiable risk factors were assessed such as; age, frailty, sex, the presence of chronic diseases, and medications. Also, the modifiable factors were assessed such as; environmental hazards, body mass index, nutritional status, activity of daily (ADL) functioning, lifestyle, and the use of assistive devices. It also included questions on the adverse consequences of falls such as (fracture, head trauma, bleeding, cut wound, abrasions, back pain, loss of consciousness, fear of falling, and social isolation).

Tool 2: Timed Up and Go Test scale (TUGT) adopted from (Podsiadlo \& Richardson, 1991). It is considering the most assessment tool to assess the possibility of falls as it is frequently used to assess dynamic balance during gait and transfer tasks, mobility, and lower body strength. The test begins with the patient sitting in a chair while wearing his or her regular footwear, then is instructed to sit on a standard with his or her back against the chair back, then stands up and walks straight for three meters as fast as possible, turns around, walks back, and sits down. The test timing begins at the instruction "go" and stops when the patient sits on the chair. The average time taken by the elderly person was between 8.1 to 11.3 seconds, TUGT took more than 12 seconds is associated with fall risk.

Tool 3: Katz Index of Independence in activities of daily living (ADLs): It was developed by (Katz et al., 1970) and used to identify the ability to perform ADL. The index ranks the adequacy of performing the main six functions of bathing, dressing, toileting, transferring, continence, and feeding. Patients' responses are scored yes or no for independence in each of these six functions. A score of six specified the full function, a score of four indicates moderate impairment, and a score of two or less indicates severe functional impairment.
Tool 4: Mini Nutritional Assessment - Short Form (MNA-SF) questionnaire adopted from (Kaiser et al., 2009): It is generally used as a quick and simple method of identifying an elderly person who at risk for malnutrition, or who is already malnourished. It included questions about declined food intake, weight loss over the past three months, mobility, if the patient affected by psychological stress or acute disease, and BMI. The total screening score was calculated and categorized as the following; a score of (12 to 14 points) indicates normal nutritional status, a score of ( 8 to 11 points) signifies that the elderly person at risk of malnutrition, and the score of (0 to 7 points) indicates malnourished.

Validity and reliability of the tools:

The study tools were submitted to a panel of three experts within the field of the study (community nursing and geriatric nursing at Minia University) to check the content validity. All panel members agreed that the current study tools were valid and relevant to the purpose of the study. While the reliability of tools was performed to confirm its consistency by using $\alpha$ coefficient test. Mini nutritional assessment scale, Katz scale, and TUGT test established a high internal consistency with alpha coefficients of $(0.86,0.88$, and $87.0 \%$ ) for them respectively which consequently revealed high reliability.

Pilot study:

A pilot study was carried out on ten percent of the total sample to assess the applicability and clarity of the constructed questionnaire, to decide the time needed to answer the questions, and to discover any problems that might arise during the actual collection of data. They included in the total sample because no modifications needed to be done in the data collection tools.

Fieldwork:

Before starting any step within the study, official permission was taken to perform the study from the administrators of the outpatient clinics and the geriatric homes where the study was intended to be conducted, also, from the ethical and research committee of the Faculty of Nursing-Minia University. Data collection for this study was carried out over a period of 6 months from the start of November 2019 till the end of April 2020. After taking the approval and informed consent to conduct the study, data were collected throughout 3 days/week by using face to face interviewing questionnaire with each participant by the researchers individually using the studied tools. The number of participants involved in every meeting was (from 4 to 6 clients).

Firstly, verbal consent was obtained from the participants after the explanation of the study objectives and informing them that the participation 
is voluntary and they had the right to refuse the participation. Furthermore, they can terminate the interview at any time and told them that confidentiality of the information was assured. After that, the researchers carried out a face-to-face interview with each elderly. The questions about personal data, medical history, health-related data, environmental factors, modifiable and nonmodifiable factors, and adverse consequences of falls were completed from the clients that took about 15 20 minutes, and then the remaining three tools were used in order to assess nutritional status, ADL functioning, and TUGT for each participant which took about 15-20 minutes. Hence, the total needed time was 30-40 minutes.

\section{Ethical considerations:}

An approval was accomplished from the administrative personal of the outpatients and the geriatric homes. The aim of the study and its implication was explained to the administrators and participants. Oral consent was obtained from the participants who were willing to participate in the study. Participants were informed that their participation are going to be on voluntary, and anonymity and confidentiality of the participants were maintained at all times.

Statistical analysis:

The data were coded, entered, and analyzed by means of the statistical package for social science (SPSS Inc., Chicago, IL, USA), version 20. Data were presented using statistics in the form of frequencies and percentages. Interval and ratio variables were presented in the form of means and SD. The $\chi^{2}$-test and correlation were used to determine the relationship among the study variables. The significance level was chosen and established as Pvalue less than 0.05 .

\section{Results:}

Table (1): Frequency distribution of the demographic characteristics for the participants according to the risk for falling based on the TUGT.

\begin{tabular}{|c|c|c|c|c|}
\hline \multirow{2}{*}{$\begin{array}{l}\text { Demographic } \\
\text { characteristics }\end{array}$} & \multicolumn{2}{|c|}{ At risk for falling } & \multirow{2}{*}{$\begin{array}{c}\% \text { for total } \\
\text { sample }(n=384)\end{array}$} & \multirow[t]{2}{*}{ P value } \\
\hline & Yes $(n=175)$ & No $(n=209)$ & & \\
\hline $\begin{array}{l}\text { Age: } \\
\text { Mean } \pm \text { SD }\end{array}$ & $66.8 \pm 5.8$ & $64.7 \pm 5.1$ & $66.1 \pm 5.6$ & $\begin{array}{c}\mathrm{t}=5.5 \\
\mathrm{p}<0.001\end{array}$ \\
\hline $\begin{array}{l}\text { Sex: } \\
\text { Male } \\
\text { Female }\end{array}$ & $\begin{array}{l}81(46.3 \%) \\
94(53.7 \%)\end{array}$ & $\begin{array}{l}105(50.2 \%) \\
104(49.8 \%)\end{array}$ & $\begin{array}{l}186(48.4 \%) \\
198(51.6 \%)\end{array}$ & $\begin{array}{l}x^{2}=0.6 \\
p>0.05\end{array}$ \\
\hline $\begin{array}{l}\text { Setting: } \\
\text { Community dwelling } \\
\text { Geriatric home }\end{array}$ & $\begin{array}{c}109(62.3 \%) \\
66(37.7 \%)\end{array}$ & $\begin{array}{c}98(46.9 \%) \\
111(53.1 \%)\end{array}$ & $\begin{array}{l}207(53.9 \%) \\
177(46.1 \%)\end{array}$ & $\begin{array}{l}x^{2}=9.1 \\
p<0.05\end{array}$ \\
\hline $\begin{array}{l}\text { Education: } \\
\text { Illiterate } \\
\text { Read and write } \\
\text { Primary } \\
\text { Secondary and higher }\end{array}$ & $\begin{array}{l}15(8.6 \%) \\
15(8.6 \%) \\
84(48.0 \%) \\
61(34.9 \%) \\
\end{array}$ & $\begin{array}{c}10(4.8 \%) \\
29(13.9 \%) \\
33(15.8 \%) \\
137(65.6 \%) \\
\end{array}$ & $\begin{array}{c}25(6.5 \%) \\
44(11.5 \%) \\
117(30.5 \%) \\
198(51.6 \%) \\
\end{array}$ & $\begin{array}{l}x^{2}=54.3 \\
p<0.001\end{array}$ \\
\hline $\begin{array}{l}\text { Working condition: } \\
\text { Still Work } \\
\text { Not work }\end{array}$ & $\begin{array}{c}7(4.0 \%) \\
168(96.0 \%)\end{array}$ & $\begin{array}{c}36(17.2 \%) \\
173(82.8 \%)\end{array}$ & $\begin{array}{c}43(11.2 \%) \\
341(88.8 \%)\end{array}$ & $\begin{array}{c}x^{2}=16.75 \\
p<0.001\end{array}$ \\
\hline $\begin{array}{l}\text { Marital status: } \\
\text { Single } \\
\text { Married } \\
\text { Widow } \\
\text { Divorced } \\
\end{array}$ & $\begin{array}{c}4(3.2 \%) \\
67(38.3 \%) \\
83(47.4 \%) \\
21(12.0 \%)\end{array}$ & $\begin{array}{c}0(0.0 \%) \\
73(34.9 \%) \\
96(45.9 \%) \\
40(19.1 \%) \\
\end{array}$ & $\begin{array}{c}4(1.0 \%) \\
140(36.5 \%) \\
179(46.6 \%) \\
61(15.9 \%) \\
\end{array}$ & $\begin{array}{l}x^{2}=8.2 \\
p<0.05\end{array}$ \\
\hline $\begin{array}{l}\text { Income: } \\
\text { Not enough } \\
\text { Enough } \\
\text { Enough and saved }\end{array}$ & $\begin{array}{c}130(74.0 \%) \\
45(25.7 \%) \\
0(0.0 \%)\end{array}$ & $\begin{array}{c}83(39.7 \%) \\
110(52.6 \%) \\
16(7.7 \%)\end{array}$ & $\begin{array}{c}213(55.5 \%) \\
155(40.4 \%) \\
16(4.2 \%)\end{array}$ & $\begin{array}{l}x^{2}=51.01 \\
p<0.001\end{array}$ \\
\hline
\end{tabular}


TUGT: Timed Up and go test. Based on this test, the participants were classified into two groups (The persons who are at risk for falling (took $\geq 12$ seconds) and those who are not at risk for falling (took $<12$ seconds).

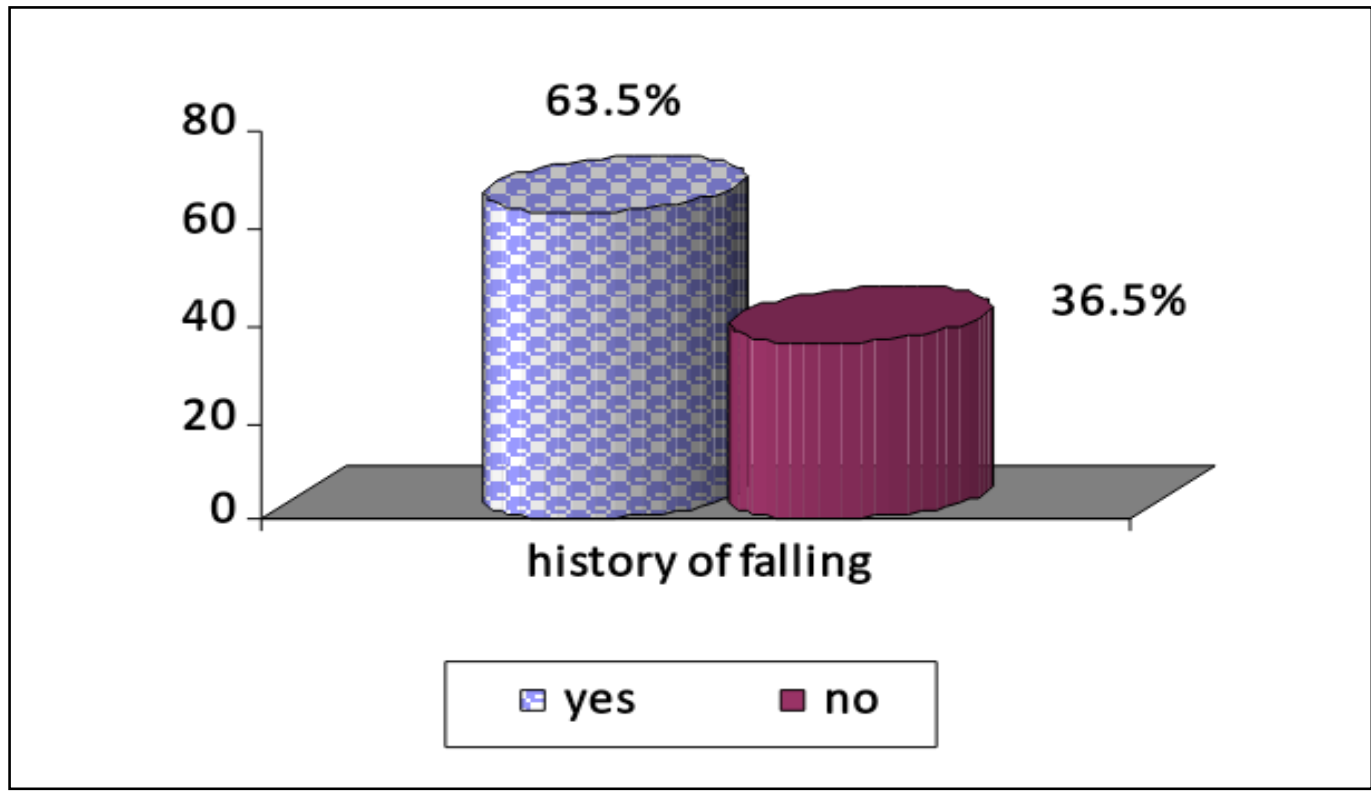

Figure (1): Percentage distribution of the total studied sample according to their history of falling.

Table (2): Distribution of the non-modifiable risk factors for falling among the studied sample.

\begin{tabular}{|c|c|c|c|}
\hline \multirow[t]{2}{*}{ Non-modifiable factors } & \multicolumn{2}{|c|}{ Falling history } & \multirow[t]{2}{*}{ P value } \\
\hline & $\begin{array}{c}\text { Faller group } \\
(n=244)\end{array}$ & $\begin{array}{c}\text { Non faller } \\
\text { group }(n=140)\end{array}$ & \\
\hline Age (mean \pm SD) & $69.8 \pm 6.6$ & $62.0 \pm 5.1$ & $\mathrm{P}<0.001$ \\
\hline $\begin{array}{l}\text { Sex: } \\
\text { Male } \\
\text { Female }\end{array}$ & $\begin{array}{c}96(39.3 \%) \\
148(60.7 \%)\end{array}$ & $\begin{array}{l}90(64.3 \%) \\
50(35.7 \%)\end{array}$ & $\mathrm{p}<0.001$ \\
\hline \multicolumn{4}{|l|}{ Chronic diseases\# } \\
\hline Diabetes mellitus & $181(74.2 \%)$ & $9(6.4 \%)$ & $\mathrm{p}<0.001$ \\
\hline Hypertension & $175(71.7 \%)$ & $13(9.3 \%)$ & $\mathrm{p}<0.001$ \\
\hline Cardiac disease & $105(43.0 \%)$ & $12(8.6 \%)$ & $\mathrm{p}<0.001$ \\
\hline Renal disease & $30(12.3 \%)$ & $0(0.0 \%)$ & $\mathrm{p}<0.001$ \\
\hline Parkinson's disease & $35(14.3 \%)$ & $5(3.6 .0 \%)$ & $\mathrm{p}<0.001$ \\
\hline Thyroid disorder & $25(10.2 \%)$ & $0(0.0 \%)$ & $\mathrm{p}<0.001$ \\
\hline Cancer & $31(12.7 \%)$ & $2(1.4 \%)$ & $\mathrm{p}<0.001$ \\
\hline Asthma & $116(47.5 \%)$ & $4(2.9 \%)$ & $\mathrm{p}<0.001$ \\
\hline Arthritis & $152(62.3 \%)$ & $15(10.7 \%)$ & $\mathrm{p}<0.001$ \\
\hline Osteoporosis & $91(37.3 \%)$ & $11(7.9 \%)$ & $\mathrm{p}<0.001$ \\
\hline \multicolumn{4}{|l|}{ Medications\# } \\
\hline $\begin{array}{l}\text { Hyperglycemic } \\
\text { Antihypertensive } \\
\text { Diuretics } \\
\text { Antidepressants } \\
\text { Laxatives } \\
\text { Narcotics } \\
\end{array}$ & $\begin{array}{l}181(74.2 \%) \\
175(71.7 \%) \\
135(55.3 \%) \\
46(18.9 \%) \\
91(37.3 \%) \\
55(22.5 \%) \\
\end{array}$ & $\begin{array}{c}9(6.4 \%) \\
13(9.3 \%) \\
12(8.6 \%) \\
13(9.3 \%) \\
4(2.9 \%) \\
4(2.9 \%) \\
\end{array}$ & $\begin{array}{l}p<0.001 \\
p<0.001 \\
p<0.001 \\
p<0.001 \\
p<0.001 \\
p<0.001\end{array}$ \\
\hline Gait \& balance problems & $70(28.7 \%)$ & $0(0.0 \%)$ & $\mathrm{p}<0.001$ \\
\hline
\end{tabular}

\# More than one answer 
Table (3): Frequency distribution of the modifiable risk factors of falls among the faller group $(\mathbf{n}=\mathbf{2 4 4})$.

\begin{tabular}{|c|c|c|c|c|}
\hline Modifiable factors & $\begin{array}{c}\text { Male } \\
(n=96)\end{array}$ & $\begin{array}{l}\text { Female } \\
(n=148)\end{array}$ & $\begin{array}{c}\text { Total (244) } \\
\text { No }(\%)\end{array}$ & $\begin{array}{c}\underset{x^{2}}{p-v a l u e} \\
x^{2}\end{array}$ \\
\hline $\begin{array}{cl}\text { Hazardous home environment \# } \\
\bullet \quad \text { Poor lighting } \\
\bullet \quad \text { Inappropriate carpet } \\
\text { - Wet floor } \\
\text { - Slippery floor } \\
\bullet \quad \text { Absence of grab bars } \\
\text { - Absence of toilet seats } \\
\end{array}$ & $\begin{array}{l}36(37.5 \%) \\
48(50.0 \%) \\
16(16.7 \%) \\
38(39.6 \%) \\
86(89.6 \%) \\
86(89.6 \%)\end{array}$ & $\begin{array}{l}102(68.9 \%) \\
129(87.2 \%) \\
79(53.4 \%) \\
94(63.5 \%) \\
100(67.6 \%) \\
148(100 \%)\end{array}$ & $\begin{array}{l}138(56.6 \%) \\
177(72.5 \%) \\
95(38.9 \%) \\
132(54.1 \%) \\
186(76.2 \%) \\
234(95.9 \%)\end{array}$ & $\begin{array}{l}\mathrm{x}^{2}=23.3 \mathrm{p}<0.001 \\
\mathrm{x}^{2}=40.3 \mathrm{p}<0.001 \\
\mathrm{x}^{2}=33.1 \mathrm{p}<0.001 \\
\mathrm{x}^{2}=14.3 \mathrm{p}<0.001 \\
\mathrm{x}^{2}=15.5 \mathrm{p}<0.001 \\
\mathrm{x}^{2}=16.1 \mathrm{p}<0.001\end{array}$ \\
\hline $\begin{array}{l}\text { Walking problems\# } \\
\text { - Lack of assistive devices } \\
\text { - Do not wear shoes at home } \\
\text { - Unsuitable wear }\end{array}$ & $\begin{array}{l}80(83.3 \%) \\
50(52.1 \%) \\
38(39.6 \%)\end{array}$ & $\begin{array}{l}148(100 \%) \\
65(43.9 \%) \\
110(74.3 \%)\end{array}$ & $\begin{array}{l}228(93.4 \%) \\
115(47.1 \%) \\
148(60.7 \%)\end{array}$ & 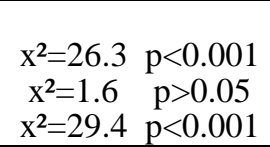 \\
\hline $\begin{array}{cl}\text { Health problems\# } \\
\qquad \text { Poor vision } \\
\text { - Poor hearing } \\
\bullet \quad \text { Urinary/fecal incontinence } \\
\bullet \quad \text { Anemia } \\
\end{array}$ & $\begin{array}{l}71(74.0 \%) \\
62(64.6 \%) \\
96(100 \%) \\
56(58.3 \%) \\
\end{array}$ & $\begin{array}{l}53(35.8 \%) \\
66(44.6 \%) \\
119(80.4 \%) \\
103(69.6 \%) \\
\end{array}$ & $\begin{array}{l}124(50.8 \%) \\
128(52.5 \%) \\
215(88.1 \%) \\
159(65.2 \%)\end{array}$ & $\begin{array}{cc}\mathrm{x}^{2}=33.9 & \mathrm{p}<0.001 \\
\mathrm{x}^{2}=9.3 & \mathrm{p}<0.05 \\
\mathrm{x}^{2}=21.3 & \mathrm{p}<0.001 \\
\mathrm{x}^{2}=3.2 & \mathrm{p}>0.05\end{array}$ \\
\hline \begin{tabular}{cl}
\multicolumn{2}{l}{ Lifestyle\# } \\
$\bullet$ & Inactivity \\
$\bullet$ & Insomnia \\
$\bullet$ & Smoking \\
$\bullet$ & Caffeinated fluids \\
Cup/day &
\end{tabular} & $\begin{array}{l}57(59.4 \%) \\
96(100 \%) \\
14(14.6 \%) \\
65(76.7 \%) \\
\end{array}$ & $\begin{array}{c}142(95.9 \%) \\
96(94.9 \%) \\
0(0.0 \%) \\
138(93.2 \%) \\
3.31 \pm 0.9\end{array}$ & $\begin{array}{c}199(81.6 \%) \\
192(78.7 \%) \\
14(5.7 \%) \\
203(83.2 \%) \\
\end{array}$ & $\begin{array}{ll}\mathrm{x}^{2}=51.7 & \mathrm{p}<0.001 \\
\mathrm{X}^{2}=42.8 & \mathrm{p}<0.001 \\
\mathrm{x}^{2}=227.6 & \mathrm{p}<0.001 \\
\mathrm{x}^{2}=27.1 & \mathrm{p}<0.001\end{array}$ \\
\hline $\begin{aligned} \text { Nutritional status: } \\
\text { - } \\
\text { - } \\
\text { - } \\
\text { At risk of malnolnurished }\end{aligned}$ & $\begin{aligned} 45 & (46.9 \%) \\
0 & (0.0 \%) \\
51 & (53.1 \%)\end{aligned}$ & $\begin{array}{l}51(34.5 \%) \\
45(30.4 \%) \\
52(35.1 \%)\end{array}$ & $\begin{array}{l}96(39.3 \%) \\
45(18.4 \%) \\
103(42.2 \%)\end{array}$ & $\mathrm{x}^{2}=35.9 \mathrm{p}<0.001$ \\
\hline $\begin{aligned} \text { BMI categories: } \\
\text { - Under weight } \\
\text { - Normal weight } \\
\text { - Overweight } \\
\text { - } \\
\text { Obese } \\
\end{aligned}$ & $\begin{array}{c}14(14.6 \%) \\
51(53.1 \%) \\
31(32.3 \%) \\
0(0.0 \%)\end{array}$ & $\begin{array}{c}43(29.1 \%) \\
78(52.7 \%) \\
25(16.9 \%) \\
2(1.4 \%)\end{array}$ & $\begin{array}{c}70(23.4 \%) \\
100(52.8 \%) \\
60(23.0 \%) \\
2(0.8 \%)\end{array}$ & $\mathrm{x}^{2}=12.5 \mathrm{p}<0.001$ \\
\hline Absence of social support & $52(54.2 \%)$ & $25(16.9 \%)$ & $77(31.6 \%)$ & $\mathrm{x}^{2}=96.4 \mathrm{p}<0.001$ \\
\hline $\begin{array}{l}\text { Polypharmacy: } \\
\text { Number of used medications }\end{array}$ & $4.81 \pm 0.8$ & $4.31 \pm 0.6$ & $4.51 \pm 0.8$ & $\mathrm{p}<0.001$ \\
\hline
\end{tabular}

\# More than one answer

Table (4): Comparison between the faller and non-faller groups according to mean scores of TUGT, Katz, MNA, and BMI (n=384).

\begin{tabular}{|l|c|c|c|}
\hline Variables & Faller group $(\mathbf{n = 2 4 4 )}$ & $\begin{array}{c}\text { Non faller } \\
(\mathbf{n}=\mathbf{1 4 0})\end{array}$ & P value \\
\hline TUGT duration & $20.12 \pm 8.08$ & $10.37 \pm 1.64$ & $\mathrm{t}=14.1$ \\
$\mathrm{p}<0.001$
\end{tabular}

TUGT: timed up-and-go test- ADL: activity of daily living scale- MNA: Mini-nutritional assessment scaleBMI: Body mass index. 
Table (5): Distribution of fall-related characteristics among the faller group $(n=244)$.

\begin{tabular}{|c|c|c|c|c|}
\hline Fall-related characteristics & $\begin{array}{c}\text { Urban } \\
(\mathbf{n}=137)\end{array}$ & $\begin{array}{c}\text { Rural } \\
(\mathbf{n}=\mathbf{1 0 7})\end{array}$ & $\begin{array}{c}\text { Total }(n=244) \\
N(\%)\end{array}$ & $P$ value \\
\hline Number of falling: & $1.5 \pm 0.7$ & $2.2 \pm 0.8$ & $1.8 \pm 0.8$ & $p<0.001$ \\
\hline \multirow[t]{2}{*}{$\begin{aligned} & \text { Place of falling: } \\
& \text { Indoor } \\
& \bullet \text { Bedroom } \\
& \bullet \text { Kitchen } \\
& \bullet \text { Bathroom } \\
& \bullet \text { On stairs } \\
& \text { Outdoor }\end{aligned}$} & $\begin{aligned} 37 & (27.0 \%) \\
2 & (1.5 \%) \\
40 & (29.2 \%) \\
58 & (42.3 \%)\end{aligned}$ & $\begin{array}{c}5(4.5 \%) \\
0(0.0 \%) \\
80(74.8 \%) \\
22(20.6 \%)\end{array}$ & $\begin{array}{c}42(17.2 \%) \\
2(0.8 \%) \\
120(49.2 \%) \\
80(32.8 \%)\end{array}$ & $\mathrm{P}<0.001$ \\
\hline & $31(22.6 \%)$ & $25(23.4 \%)$ & $56(23.0 \%)$ & $p>0.05$ \\
\hline $\begin{aligned} & \text { Fall time: } \\
&$\[ \]$ \text { Morning } \\
& \bullet \text { Afternoon } \\
& \bullet \text { Night }\end{aligned}$ & $\begin{array}{l}70(51.1 \%) \\
23(16.8 \%) \\
44(32.1 \%)\end{array}$ & $\begin{array}{c}57(53.3 \%) \\
7(6.5 \%) \\
43(40.2 \%)\end{array}$ & $\begin{array}{c}127(52.0 \%) \\
30(12.3 \%) \\
87(35.7 \%)\end{array}$ & $\mathrm{P}<0.05^{*}$ \\
\hline
\end{tabular}

Table (6): Distribution of the falling adverse consequences among the faller group $(n=244)$.

\begin{tabular}{|c|c|c|c|c|}
\hline Adverse consequences & $\begin{array}{l}\text { Male } \\
(n=96)\end{array}$ & $\begin{array}{l}\text { Female } \\
(n=148)\end{array}$ & $\begin{array}{c}\text { Total }(n=244) \\
N(\%)\end{array}$ & $P$ value \\
\hline $\begin{aligned} & \text { Physical consequences: } \\
& \bullet \text { Cut wound and } \\
& \text { abrasion } \\
& \bullet \text { Head trauma } \\
& \bullet \text { More than one injury } \\
& \bullet \text { Bleeding } \\
&- \text { Fracture } \\
& \bullet \text { Joint dislocation } \\
&- \text { Back pain } \\
&\end{aligned}$ & $\begin{aligned} 37 & (38.5 \%) \\
0 & (0.0 \%) \\
28 & (29.1 \%) \\
27 & (28.1 \%) \\
51 & (53.1 \%) \\
28 & (29.1 \%) \\
55 & (57.3 \%)\end{aligned}$ & $\begin{aligned} & 49(33.1 \%) \\
& 4(2.7 \%) \\
& 27(18.2 \%) \\
& 4(2.7 \%) \\
& 14(9.5 \%) \\
& 13(8.8 \%) \\
& 123(83.1 \%)\end{aligned}$ & $\begin{array}{c}86(35.2 \%) \\
4(1.6 \%) \\
55(25.3 \%) \\
31(12.7 \%) \\
65(26.6 \%) \\
40(16.4 \%) \\
178(73.0 \%)\end{array}$ & $\begin{array}{l}P>0.05 \\
P>0.05 \\
P>0.05 \\
P<0.001 \\
P<0.001 \\
P<0.001 \\
P<0.001\end{array}$ \\
\hline $\begin{array}{c}\text { Psychological consequences: } \\
\qquad \quad \text { Anxiety } \\
\text { - Fear of future falls }\end{array}$ & $\begin{array}{c}45(46.9 \%) \\
96(100.0 \%)\end{array}$ & $\begin{array}{l}45(30.4 \%) \\
148(100 \%)\end{array}$ & $\begin{array}{l}90(36.9 \%) \\
244(100 \%)\end{array}$ & $\mathrm{P}<0.05$ \\
\hline
\end{tabular}

Table (7): Correlation between duration of TUGT and (age, ADL, MNA, and number of medications) for studied sample.

\begin{tabular}{|l|c|c|}
\hline \multirow{2}{*}{ Variables } & \multicolumn{2}{c|}{ Duration of TUGT in seconds } \\
\cline { 2 - 3 } & $\mathbf{r}$ & P value \\
\hline Age & 0.3 & $\mathrm{P}<0.001$ \\
\hline ADL mean score & $0.2-$ & $\mathrm{P}<0.001$ \\
\hline MNA mean score & $0.2-$ & $\mathrm{P}<0.001$ \\
\hline Number of used medications & 0.6 & $\mathrm{P}<0.001$ \\
\hline
\end{tabular}

TUGT: timed up-and-go test- ADL: activity of daily living scale-MNA: Mini-nutritional assessment scale.

Table (1): Shows that $(\mathrm{n}=175)$ represented $45.6 \%$ of whole sample were at risk for falling based on the performed timed up and go test (TUGT), with the mean age of $(66.8 \pm 5.8)$, near to half of them were males, and $62.3 \%$ of them were a communitydwelling. Also the table illustrated that $(47.4 \%$, $48.0 \%$, and $74.0 \%$ ) of those at falling risk were widow, had primary education and insufficient income.

Figure (1): Reflects that $63.5 \%$ of the total studied sample had a history of falls through the last six months which indicated the magnitude of the problem with this high percentage.
Table (2): Illustrates that the advanced age, sex, chronic diseases, medications, and balance problems were the most documented non-modifiable risk factors for falling among the faller group, in which $(60.7 \%)$ of the fallers were females, $74.7 \%$ and 71.7 of them had diabetes and hypertension respectively, followed by arthritis, asthma, heart disease, and osteoporosis in proportions of $(62.3 \%, 47.5 \%, 43.0 \%$, and $37.3 \%$ ) respectively. Likewise, hyperglycemic, antihypertensive and diuretic medications were the commonest used medication by the faller group, with a highly statistically significant difference between 
both groups reflected by $(\mathrm{P}$-value $=0.001)$. This table answered the second research question.

Table (3): Reveals that the most reported modifiable factors of falling among the faller group included; environmental hazards, walking problems, health problems, lifestyle, nutritional status, body mass index, and absence of social support. The hazardous home environmental factors were; absence of toilet seats $(95.9 \%)$, absence of grab bars $(76.2 \%)$, inappropriate carpets $(72.5 \%)$, poor lighting $(56.6 \%)$, slippery floor $(54.1 \%)$, and wet floor $(38.9 \%)$.

Also, table (3): Illustrated that the majority of the faller group had a lack of assistive devices, $60.7 \%$ of them had unsuitable wear, while $47.1 \%$ of them had not wear shoes at home. Concerning the health problems; it was found that urinary incontinence, anemia, and poor hearing and vision took the highest percentages among the fallers. As regards lifestyle, $83.2 \%$ of the fallers were drinking coffee, $81.6 \%$ not active, more than three-quarters of them had insomnia. Furthermore, $42.2 \%$ of the faller group were malnourished, as well as (23.4\% and $23.0 \%)$ of them were underweight and overweight respectively. This table answered the first current research questions.

Table (4): Reflects the comparison between the faller and non-faller groups according to mean scores of (TUGT, Katz, MNA, and BMI). It was documented that longer TUGT duration ( $\geq 12$ seconds), ADL dependence, poor nutrition, and underweight were greater reported among the faller group and significantly associated with falls versus the nonfallers with statistical significance differences between both groups reflected by $(\mathrm{p}<0.001)$.

Table (5): Explains the fall-related characteristics among the faller group. It was clear that the mean numbers of falling were about two times, and (1.5 \pm 0.7 , and $2.2 \pm 0.8$ ) for the urban and rural residents respectively with a highly statistically significant difference between both residents reflected by $(\mathrm{P}$ value $=0.001)$. Likewise, the study revealed that indoor falling was greater than outdoor falling, as well as, falling occurred in the early morning and at the bathroom took the highest percentages among the faller group (52.0\% and $49.2 \%$ ) a respectively.

Table (6): Shows the distribution of falling adverse consequences among the faller group. It was found that back pain $(73.0 \%)$, cut wounds $(35.2 \%)$, and fractures $(26.6 \%)$ were the most reported physical consequences, while $100 \%$ of them have fear of future falling as a psychological consequence. Besides, it was clear that the elderly men experienced fractures and bleeding as negative consequences of falling greater than the elderly females with a highly significant difference between both sexes $(\mathrm{P}<0.001)$.
Table (7): Clarifies the correlations between the duration of time up and go test (TUGT) and (age, ADL score, Mini-nutritional scale score, and the number of used medications) for the studied sample. It was found that there were positive correlations between the duration of TUGT and (age and the number of medications) with $(\mathrm{p}<0.001)$. On other hand, there were negative correlations between the duration of TUGT and (ADL and mini-nutritional scores) which means that increased duration of TUGT was associated with a decrease in the ability to perform the ADL, and poor nutritional status.

\section{Discussion:}

Falling is a major public health problem among elders which accounts for more than half of injuryrelated hospitalizations worldwide and calls for global consideration (Almegbel et al., 2018). Screening for the risk factors is very important as a key of preventive efforts (Karavadi \& Raghuram, 2020). Therefore this study aimed to identify the modifiable and non-modifiable risk factors and the adverse consequences of falling among elderly people.

The findings of the current study had been discussed within the subsequent frame of references.

\section{1-Discussion of the demographic characteristics} for the participants:

Results of the current revealed that about half of the total sample was at risk for falling based on the performed TUGT and about two-thirds of them had a history of falling during the last six months. Also it was clear that the falling risk was increased with age, these findings were matching with the study conducted by (Hamed et al., 2017) in Sohag Governorate which illustrated a significant association between the falling risk and the advanced age. This fact can be explained as the normal agerelated changes like poor eyesight or poor hearing, a decline of muscle size and strength, combined with chronic conditions and the side effects of some medications can affect elders' strength and balance and consequently increase the risk of fall among older adults than younger.

Concerning sex, our results revealed that the risk of falling was increased among elderly women rather than elderly men. This can be explained from the authors' opinion that women are more likely to have chronic diseases accompanied by polypharmacy than men. This finding was supported by (Bekibele $\boldsymbol{\&}$ Gureje, 2010) who mentioned that Nigerian elderly females were reported falls more than elderly males. While it was against the study of (Cameron et al., 2018) who stated that the male gender is more at risk for falls and discussed that these different findings in different countries between both sexes may be 
attributed to biological, social, and environmental characteristics.

As regards education, results of the current study reflected an increased risk of falling among loweducated participants, and this is matching with the results of (Hopewell et al., 2018). This fact can be discussed from our view of point as the high prevalence of illiteracy among this age group especially in rural communities is commonly is greatly associated with an inability to follow the health instructions regarding the used medications, controlling chronic illnesses, adopting a healthy lifestyle, the importance of frequent checkup for visual, hearing deficits, and the blood sugar level monitoring which consequently increase the risk of falling among them.

Concerning the place of residence, our results illustrated that the percent of community-dwelling elders who were at risk for falling was higher than the percent of residents in nursing homes. This may be attributed to the number of participants had been took from the outpatient clinics was higher than the number of nursing home residents, because of a limited number of governmental geriatric homes in Minia city. This was supported by (Hamed et al., 2017) who stated that there was a limited number of governmental geriatric homes in Upper Egypt.

Additionally, another validation by (Vieira, et al., 2016) who found that more than one-quarter of the community-dwelling elderly experienced at least one episode of fall, and more than half reported recurrent falls. On other hand (Datta et al., 2019) demonstrated that the prevalence of falling among institutionalized was higher than communitydwelling elders with a percentage ranged between fifty to sixty percent.

Our study also investigated the falling related characteristics, it was found that the indoor falling that occurred in early morning and at the bathroom took the highest percentages. This can be explained as the elderly individuals are generally spent most of their time at their homes especially after retirement and have a limited of the outdoor activities.

These findings were similar to the study of (Janeiro, 2019) who found that most fallers had their falling episodes at home, and most commonly occurred in the morning at the bathroom and on stairs, also, it was matched with the studies conducted at Sohag and Menoufia Governorates by (Hamed, et al., 2017) and (Elsamahy et al., 2019) respectively and confirmed that the indoor falling took the highest percentages in their results and discussed that environmental home hazards and safety circumstances were the major causes. However, (Sulaiman et al., 2018) found that the traffic outdoor falling was higher than indoor which is opposite of our findings.
2-Discussion of the non-modifiable and modifiable risk factors of falls among the faller group: The non-modifiable factors of falling:

Our results reflected that age acts as a non-modifiable predictive of falls. This result is in accordance with the results of (Almegbel et al., (2018) who discussed that the adequate response to external disturbances, such as slipping and stumbling and to restore gait and balance is progressively declined with aging.

Additionally, our findings reflected that female gender acts as a non-modifiable risk factor of falling, and this is matching with the Nigerian study done by (Bekibele et al., 2010), but it was against the study performed in Saudi Arabia by (Almegbel et al., 2018) who illustrated that sex doesn't acts as a risk factor of falling among elders.

Also, the results of the current study displayed that diabetes, hypertension, and arthritis were the commonest reported chronic diseases among the fallers. This result is agreed with the report of the American Geriatric Society (2015) which documented that the most common chronic diseases afflicting elderly people and increased the risk of falling among them are; diabetes, cardiovascular disease, and arthritis.

Also, it was found that medication intake has been reported as non-modifiable risk factors among the faller group, especially hyperglycemic, antihypertensive, and diuretic drugs. This fact can be attributed as such medications increase the risk of postural hypotension, dizziness, drowsiness, and affect stability which may increase the likelihood of having falling episode. These findings were in agreement with the Egyptian study conducted in Sharkia Governorate, by (Mohammed et al., 2018) and showed a significant relationship between the occurrence of falls and the different types of chronic diseases, as well as the medication used.

The modifiable risk factors of falling:

In this study, different preventable and modifiable risk factors had been identified included; ADL dependency, slower TUGT, malnutrion, environmental hazards, lifestyle, lack of assistive devices, body mass index, lack of family support, and some biological conditions as; anemia, hearing and visual deficits. These findings had been discussed within the following frame of references.

It was found that elderly people who are dependent or need assistance in performing activity of daily living (ADL) were at greater risk for falling than independent seniors. This finding was supported by (Mohamed et al., 2012) who mentioned that elderly who had restrictions in walking, transfer, and balance activities are ten times more likely to report falls compared with those with no limitations. 
Concerning timed up and go test duration, it was found that the fallers were demonstrated longer duration of TUGT as compared to non-fallers. This can be discussed as; with aging, slow postural reflexes may increase the muscular force needed for an effective response to postural disturbances, as well as, the skeletal muscles strength that involved in postural control and walking declined. These conclusions were matching with the results of (Harnish et al., 2016) who found lower duration of TUGT and declined falling episodes among intervention group attended the balance and gait training exercise program.

As regards environmental circumstances, the results of the current study indicated that the absence of toilet seats, grab bars, and carpets, as well as, poor lighting and slippery floor were the most environmental hazards associated with the risk of falling. These are similar to the results of (Elsamahy et al., 2019) who reported that most falling episodes happened at bedroom and bathroom related to poor lighting and slippery floor. Authors viewed that home environmental hazards concerning the light, chair and bed height, floor surfaces, and other factors create opportunities for falls and should be integrated as an essential component of fall prevention programs by maintaining adequate arrangements and safety environment.

Furthermore, the study result showed that the majority of the studied participants had lack of assistive devices, and don't use walking aids, and this is matching with the study of (Graafmans et al., 2013) who described that the use of walking aid protected the aged person against falls. While disagree with the findings of (Sousa et al., 2017) who showed the use of walking aid was associated with a doubled risk of falling among the older population. Additionally, the current study found that about half of the faller group did not wear shoes at home. This result was supported by (Elsamahy et al., 2019) who stated that wearing suitable shoes at home was significantly minimizes the risk of falling among seniors.

Concerning the biological etiologies linked to falling among the faller group. It was found that anemia, visual and hearing problems were linked with falling risk among the fallers. These findings are similar to the results of (Janeiro, 2019) and (Saftari \& Kwon, 2018) who found a significant relationship between anemia and sensory deficits and the incidence of falls and home accidents that occurred among older adults. Lifestyle also acts as a relevant predictor of falls in this study. It was found that inactivity, drinking of caffeinated beverages, and polypharmacy were associated with the risk of falls, these findings were consistent with the results of (Abbasi et al., 2017) that studied the relation between lifestyle and incidence of falling, and documented that most fallers had mobility limitations. Also, it was similar to the results of (Sousa et al., 2017) who found that the possibility of falls increased considerably when more than four medications are taken.

Malnutrition was also reported among the fallers more than non-fallers. This was similar to the findings of (Ariel, 2020) who reported that malnutrition is considering a determinant for falling among the aged population and associated with harmful consequences of falls than normal people. This fact can be explained as the symptoms of malnutrition including; fatigue, dizziness, irritability, loss of muscle strength and mass, impulsivity, and poor judgment lead to loss of stability and increase the risk of fall.

As regards family support, it was found that lack of family support and living alone were linked to the risk of falling, and these results were supported by (Amer et al., 2018). Authors viewed that living alone is commonly associated with deprivation from the needed care which increases the risk of malnutrition, dehydration, depression, and frailty. Besides, Sleep quality is another predictive factor; these findings were consistent with the studies conducted in Malizia by (Kioh et al., 2018), and in Egypt by (Kamel et al., 2013) who documented a major association between insomnia and falls.

\section{3- Discussion for the negative consequences of falling among the faller group}

The adverse consequences of falling had been investigated in the current study. It was found that the most reported physical consequences among the faller group included; back pain, cut wounds, and fractures, added to, that the elderly men experienced fractures and joint dislocation greater than the elderly women. These findings were supported by (Chang et al., 2020) who investigated the injuries caused by falls among older Canadian and reported that cut wounds, bone fractures, and sprains were the majority of falls-related injuries. Likewise, it agrees with (Gudnadottir, 2018) who found that the most mechanical injuries as a result of fall presented among males more than females.

While it disagreed with the results of (Chang et al., 2020) who reported that pelvic fractures that occurred among elderly women were three times higher than men, and discussed that elderly women are commonly suffering from progressive loss of bone density as a result of multiple pregnancies, lactation, and postmenopausal hormonal changes which affect calcium level. Concerning the psychological consequences of falling, almost of the faller group had a fear and anxiety of future falling. This was 
agreed with (Amer., 2018) who stated that there is a close relationship between anxiety and falling.

4- Discussion of the Correlations between duration of TUGT and (age, ADL, MNA, and number of medications) for studied sample

Finally, the results of the present study revealed positive correlations between the duration of timed up and go to test (TUGT) and (age and the number of used medications). These findings were similar to those of (Zarzeczny et al., 2017 \& Sulaiman, 2018) who found that TUGT score was significantly affected by the age and discussed that the aging progression is connected with a gradually decline in muscle mass and strength of lower limbs leads to mobility restriction and reflected a decrease in functional test performances.

On other hand, our results revealed negative correlations between the duration of TUGT and (ADL and mini-nutritional scores). This can be discussed as a limited physical activity and malnutrition is strongly associated with low muscle strength and consequently increased the risk of falls and its complication with aging. These findings were greatly supported by (Pigłowska et al., 2020) who demonstrated a decreased duration of TUGT among older adults with increased ADL and mini-nutritional scales scores and recommended that improving functional activities and nutritional status are preventable actions of falling.

\section{Study limitations:}

1.The results of the current study are of local nature and can't be generalized to the whole elderly population at the national level.

2.Some participants were afraid and worried to report falling that happened for them either in their personal homes or in the geriatric homes.

\section{Conclusion:}

Age, female sex, and chronic diseases were the main non-modifiable risk factors of falling, added to, slower TUGT, hazardous environment, declined ADL function, walking problems, lifestyle, malnutrition, lack of assistive devices, and body mass index were the detected risk factors that can be modified to prevent falling, additionally back pain, cut wounds, fractures, and fear from future falling were the most reported adverse consequences of falling among the fallers.

\section{Recommendations:}

Based on the findings of the study, the following recommendations were suggested:

1- Early detection for the modifiable risk factors is essential for preventing falling and its adverse consequences among elderly people.
2- Educational intervention for the health care providers at the governmental as well as the private geriatric homes is recommended focusing on assessment, prevention, intervention, and environmental safety against falls.

3- Use of fall risk assessment instrument as a routine part of physical examination for older adults at all health care settings and institutions in Upper Egypt.

4- Further studies are needed to be community-based and intervention in nature aimed at raising awareness of elderly people and caregivers about the preventable risk factors, balance training exercise, and elimination of environmental hazards.

\section{References}

- Abbasi M., Daniali S., \& Hazrati M. (2017): Lifestyle of Fallen Elderly Patients Referred to Isfahan Hospitals. IJN; 30 (107):20-31.

- Abusaaq H., (2015): population aging in Saudi Arabia.http://www.sama.gov.sa/enUS/EconomicR esearch/WorkingPapers/populationaging in saudi arabia.

- Almegbel FY., Alotaibi IM., \& Alhusain FA. (2018): Period prevalence, risk factors, and consequent injuries of falling among the Saudi elderly living in Riyadh, Saudi Arabia: a crosssectional study. BMJ Open 2018; 8:e019063.

- Amer M., Abdellah A., \& Elsayed E. (2018): Fear of falls among nursing homes residents and community dwelling elderly. The Egyptian Journal of Hospital Medicine. Vol. 73 (5), Page 6785-6788

- American Geriatrics Society (AGS) (2015): Clinical practice guideline: for prevention of falls in older persons [Internet]. Cited 2015 Jul 15]. Available

from http://www.americangeriatrics.org/health_care_pr ofessionals/clinical_practice/clinical_guidelines_r ecommendations/2010.

- Ariel S., (2020): The association of malnutrition with falls and harm from falls in hospital inpatients: Findings from a 5-year observational stud. J Clin Nurs; 29:429-436.

- Bekibele C., \& Gureje O., (2010): Fall incidence in a population of elderly persons in Nigeria. Gerontology; 56:278-83.

- Bok A., Pierce L., Gies C., \& Steiner V. (2016): Meanings of falls and prevention of falls according to rehabilitation nurses: A qualitative descriptive study.Rehabilitation Nursing, 41, 4553.

- Cameron E., Susan K., \& Melissa K. (2018): Falls and long-term care: a report from the care by 
design observational cohort study. BMC Family Practice 19:73, 261-269.

- Central Agency for Public Mobilization and Statistics, Egypt (2017).

- Chang VC., Kuran N., \& Thompson W. (2020): Fall-related injuries among Canadian seniors. Health Promotion and Chronic Disease Prevention in Canada Research, Policy and Practice. Vol 35, No 7, 99-108.

- Datta A., Datta R., \& Elkins J. (2019): What Factors Predict Falls in Older Adults Living in Nursing Homes: A Pilot Study. J. Int. J. Environ. Res. Public Health, 15, 498.

- Dolatabadi E, Ooteghem KV, Taati B, \& Iaboni A. (2018): Quantitative Mobility Assessment for Fall Risk Prediction in Dementia: A Systematic Review. Dement Geriatr Cogn Disord; 45:353-367.

- Elsamahy EA, ELSayed EM, \& BadrEldin SA. (2019): Risk Factors for fall among Elderly in a Rural Community in El-Monofya Governorate. Saudi Journal of Nursing and Health Care; 2(1): $1-14$.

- Florence C, Bergen G, Atherly A, Burns E, Stevens J, \& Drake C. (2018): Medical Costs of Fatal and Nonfatal Falls in Older Adults. J Am Geriatr Soc; 66(4):693-698.

- Gomes EC., Marques AP, Leal MC., \& Barros BP. (2016): Factors associated with the danger of accidental falls among institutionalized elderly individuals: an integrative review. iênc Saúde Coletiva;19(8):3543-51.

- Graafmans WC, Lips PS, \& Wijlhuizen GJ. (2013): Daily physical activity and the use of a walking aid in relation to falls in elderly people in a residential care setting. Z Gerontol Geriatr; 36:23-8.

- Gudnadottir M., Thorsteinsdottir T., Mogensen B., Aspelund T., \& Thordardottir E. (2018): Accidental injuries among older adults. International Emergency Nursing.Volume 40, Pages 12-17.

- Hamed F., Mohammed A., \& Aly Y., (2017): Elderly Falls Prevalence and Associated Factors in Sohag Governorate .The Egyptian Journal of Community Medicine Vol. 35, 134.

- Harnish A., Dieter W., Crawford A., \& Tiffany E. (2016): Effects of EvidenceBased Fall Reduction Programing on the Functional Wellness of Older Adults in a Senior Living Community: A Clinical Case Study. Front Public Health. 2016; 4: 262.

- Hopewell S., Adedire O., Copsey B., Boniface G., Sherrington C., Clemson L., Close J., \& Lamb S. (2018): Multifactorial and multiple component interventions for preventing fall in older people living in the community. Cochrane Database of Systematic Reviews, Issue 7.

- Ilha SA., Quintana JM., Santos SC., Vidal DA., Gauterios DP., \& Backes DS. (2014): Falls in elderly people: reflection for nurses and other professionals. Rev Enferm UFPE. 8(6):1791-98.

- Ismail GH., Fahim H., Bakr I., Wassif G., \& Hamza S., (2018): Risk of falls and Effect of a Health Education Program in Prevention of Falls among Elderly in Geriatric Homes in Cairo, Egypt. EJGG.; 5(2): 1-7.

- Janeiro R., (2019): Falls and associated factors among elderly residing in the community; Geriatr. Gerontol., Rev. Bras. 21(5): 532-541.

- Jankowska P, Jankowski K, \& Rudnicka D. (2018): Elderly falls, multifactorial medical problem - how to assess the risk? Journal of Education, Health and Sport. 8(9):61-68.

- Jonkman N., Del Panta V., Hoekstra T., \& Colpo M. (2018): "Predicting Trajectories of Functional Decline in 60- to 70-Year-Old People" Gerontology 2018; 64:212-221.

- Kaiser MJ., Bauer JM., \& Ramsch C. (2009): Validation of the Mini Nutritional Assessment Short-Form (MNA-SF): A practical tool for identification of nutritional status. J Nutr Health Aging; 13:782-788.

- Kamel MH, Abdulmajeed AA, \& Ismail SS. (2013): Risk factors of falls among elderly living in urban Suez-Egypt. Pan Afr Med J.;14:26

- Karavadi V., \& Raghuram V., (2020): Risk status of falls: A study among the elderly residing in selected old-age homes, Bengaluru. Int J Med Sci Public Health; 9(1):7-10.

- Kioh SH., \& Rashid A. (2018): The prevalence and the risk of falls among institutionalized elderly in Penang, Malaysia. Med J Malaysia Vol 73 No 4, 45-50.

- Katz S., Down TD., Cash, HR., \& Grotz, RC. (1970): Progress in the development of the index of ADL. The Gerontologist, 10(1), 20-30.

- Maggi P., Johanna A., Sam D, Sophie C. \& Anja D. (2018): Fall determinants and home modifications to prevent falls. Canadian J.of Occupational Therapy., Vol. 85(1) 79-87.

- Maneeprom N., Taneepanichskul S., \& Panza A. (2018): Falls among physically active elderly in senior housings. Clinical Interventions in Aging: 13 2149-2159.

- Meysamie A., Taee F., Mohammadi-Vajari M., YoosefiKhanghah S., Emamzadeh-Fard S., \& Abbassi M. (2014): Sample size calculation on web, can we rely on the results? Journal of Medical Statistics and Informatics.ISSN.20537662. 
- Mohammed AE, Orabi EE, \& Hennery H., (2018): Falls among the elderly in rural areas of the Sharkia Governorate, Egypt. Turk J Public Health; 16(3).

- Mohammed S. Khater, M, Shereen T. \& Mousa, M (2012): Predicting falls among Egyptian nursing home residents: A 1-year longitudinal study. J. of Clinical Gerontology \& Geriatrics. 3; 73-76.

- Morley JE, Abbatecola AM, \& Woo J. (2017): Management of comorbidities in older persons with type 2 diabetes. J Am Med Dir Assoc; 18:639-645.

- National Center for Injury Prevention and Control (2015): Preventing Falls: A Guide to Implementing Effective Community-Based Fall Prevention Programs. Available from: https://www.cdc.gov/homeandrecreationalsafety/p df/falls/fallpreventionguide-2015-a.pdf.

- Pigłowska M., Guligowska A., \& Kostka T., (2020): Nutritional Status Plays More Important Role in Determining Functional State in Older People Living in the Community than in Nursing Home Residents. Nutrients, 12, 2042.

- Podsiadlo D., \& Richardson S. (1991): The Time "Up \& Go": A test of basic functional mobility for frail elderly persons, J. Amer. Geriatr. Soc. 39:142-148.

- Saftari L., \& Kwon O., (2018): Ageing vision and falls: a review. journal of Physiological Anthropology 11:37.

- Sharif SI, Al-Harbi AB, Al-Shihabi AM, AlDaour DS, \& Sharif RS. (2018): Falls in the elderly: assessment of prevalence and risk factors. Pharmacy Practice; 16(3):1206.

- Soto-Varela A., Faraldo-García A., RossiIzquierdo M., \& Vaamonde I. (2017): Adherence of olderpeople with instability in vestibular rehabilitation programmes: prediction criteria. J LaryngolOtol; 131: 232-238.

- Sousa LM, Marques-Vieira CM, \& Caldevilla MN, (2017): Risk for falls among communitydwelling older people: systematic literature review. Rev Gaucha Enferm; 37:144-149.

- Sulaiman A., (2018): Falls among elderly and its relation with their health problems and surrounding environmental factors in Riyadh. J Family Community Med. 2018 Jan-Apr; 25(1): 29-34.

- Tinetti ME., Han LM., Lee DS., \& Gross CP. (2014): Antihypertensive medications and serious fall injuries in a nationally representative sample of elderly. JAMA Intern Med; 174:588-95.

- Vieira E., Palmer R., \& Chaves P., (2016): Prevention of falls in older people living in the community. BMJ, 353, i1419.
- World Health Organization (2018): Falls. Available from: http://www.who.int/newsroom/fact-sheets/detail/falls.Accessed June 12, 2018.

- World Health Organization (2006): BMI

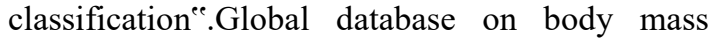
index.

.http://apps.who.int/bmi/index.jsp?introPage=intr o_3.html.

- Zarzeczny R., Agnieszka S., Anna P., Jakub M., Kieltyka A., Matyja B., \& Dudek M. (2017): Aging effect on the instrumented TimedUp-and-Go test variables in nursing home women aged 80-93 years. Biogerontology; 18(4): 651663.

- Zhang L., Ding Z., Qiu L., \& Li. A. (2019): Falls and risk factors of falls for urban and rural community-dwelling older adults in China. Zhang et al. BMC Geriatrics 19:379. 